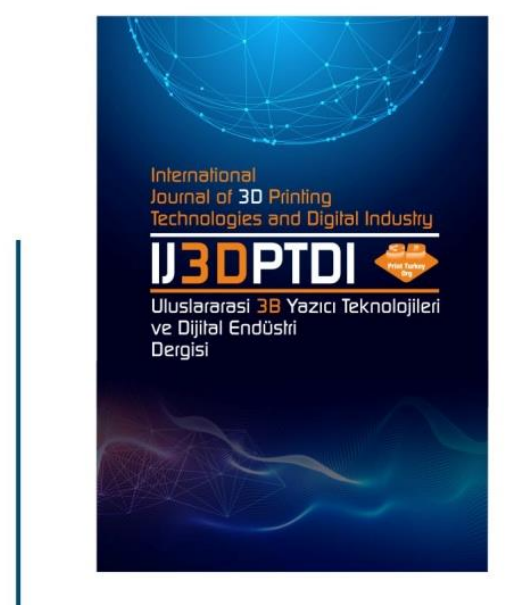

ULUSLARARASI 3B YAZICI TEKNOLOJILERI

VE DIJITAL ENDÜSTRI DERGISI

INTERNATIONAL JOURNAL QF 30 PRINTING TECHNQLOGIES AND DIGITAL INDUSTRY

I55N:2602-3350 [Online]

URL: https://dergipark.org.tr/ij3dptdi

\title{
DETERMINING OPTIMAL ROBOCASTING PROCESS PARAMETERS FOR ADDITIVE MANUFACTURING OF CERAMIC PARTS
}

Yazarlar (Authors): Cem Okyay ${ }^{\mathbb{D}}$, Binnur Sagbas ${ }^{(\mathbb{D}) *}$

Bu makaleye şu şekilde atıfta bulunabilirsiniz (To cite to this article): Okyay C., Sagbas B. "Determining Optimal Robocasting Process Parameters For Additive Manufacturing Of Ceramic Parts", Int. J. of 3D Printing Tech. Dig. Ind., 5(3): 435-444, (2021). 


\title{
DETERMINING OPTIMAL ROBOCASTING PROCESS PARAMETERS FOR ADDITIVE MANUFACTURING OF CERAMIC PARTS
}

\author{
Cem Okyay ${ }^{\mathrm{a}}$, , Binnur Sagbas $^{\mathrm{b}}$ (D)* \\ ${ }^{a}$ Kalekalip Makina ve Kalip San. A.S., 34295 Kucukcekmece, Istanbul, Turkey \\ ${ }^{b}$ Department of Mechanical Engineering, Yildiz Technical University, 34349 Besiktas, Istanbul, Turkey \\ *Correponding Author: bsagbas@gmail.com
}

(Received: 29.03.2021; Revised: 05.10.2021; Accepted: 09.11.2021)

\begin{abstract}
Additive Manufacturing (AM) is rapidly growing and widely used manufacturing technology for building up functional parts by metal, polymer, ceramic and their composites. Different AM methods have been developed for processing various materials in different feed stock such as filament, powder, resin, etc. Robocasting is one of the AM method for building up 3D ceramic based geometries. Although, the method most commonly used in biomedical industry for generating ceramic tissue scaffolds and artificial organs, it is also promising method for manufacturing industrial ceramic products such as bathtubs, sinks and vases. But there is lack of study about industrial application of the robocasting process and there are gaps for defining effective optimal process parameters for increasing process efficiency and product quality especially in industrial huge parts. In this study, it is aimed to determine optimal process parameters for building up ceramic vase with high surface quality and dimensional accuracy. Nozzle diameter and material extrusion rate were changed in different levels and manufactured parts were inspected in terms of their dimensional accuracy and surface quality via precision measurement systems. The results revealed that, nozzle diameter and extrusion rate were important parameters and they have to be selected in accordance with each other for improving product quality.
\end{abstract}

Keywords: Additive manufacturing. Ceramic. Robocasting. Dimensional Accuracy. Surface Quality.

\section{INTRODUCTION}

Additive manufacturing (AM) is rapidly developing technology which provides flexibility in customeroriented, personalized manufacturing of complex 3D geometries. By eliminating the need of tools, fixtures and molds AM technologies have a wide range of application area, such as in aerospace, architecture, automotive, defense and biomedical industries [1]. In order to provide effective systems for different materials in such a wide range of usage area, different AM methods have been developed. According to the American Society for Testing and Materials (ASTM) group, ASTMF42-Additive Manufacturing committee, AM methods have been classified in seven basic categories such as, Vat Photo Polymerization (Stereolithography, bio plotters), Powder Bed Fusion (Selective Laser Sintering (SLS), Selective Laser Melting (SLM), Electron Beam Melting (EBM), Direct Metal Laser Sintering (DMLS)), Material Extrusion (Fused Deposition Modeling (FDM)), Material Jetting (Multi-jet Fusion Technology), Binder Jetting, Directed Energy Deposition (Laser Engineered Net Shaping, Direct Metal Deposition) and Sheet lamination [2-3].

Metals such as Ti6Al4V [4], AlSi10Mg [5], stainless steel [6], Inconel [7], polymers such as polylactic acid (PLA) [8], acrylonitrile butadiene styrene (ABS), polyamide (PA) [9] and their composites are most widely used materials in these systems. Besides these common materials ceramics and their composites have attracted great interest of manufacturers and researchers by having excellent thermal resistance, surface hardness, wear resistance and biocompatibility. However, due to the high melting point of the 
ceramics and the need for heat treatment for obtaining solid structure after building, additive manufacturing methods for processing ceramic materials are limited [10].

Robocasting, also called as direct-ink-writing is one of most common method for additive manufacturing of ceramic based materials [1]. The method provides opportunity to generate 3D ceramic parts without support structures which is the most important advantage of the system. Although the robocasting method is very similar to the material extrusion AM method [11], there is a very important feature for ceramic materials that distinguishes the robocasting method from the material extrusion. This feature is not using any heating near the nozzle in order to ensure the fluidity of the material in the robocasting method. Ceramic paste (mud), which is a viscous aqueous solution of desired ceramic powder fed to the nozzle. Feeding of the material to the nozzle is usually achieved by the pressurized air supplied by a compressor pushing the plunger [12]. In this way, it reduces the risk of cracks occurring by sudden heating of the ceramic material [13-14]. The nozzle moves according to the defined tool path on CAD data to generate 3D geometry layer-by-layer [15]. Robocasting is capable of building green body which needs sintering afterwards [10].

Taking into account their physicochemical properties and low costs, clay materials are generally used as the main raw material in the production of traditional ceramic parts [16]. The applications of clay minerals depend on their composition, structure and physical properties since they undergo many physical and chemical changes that determine the ceramic properties predominantly during the baking of clay materials [16]. In other words, the properties of clay minerals varying with baking temperatures determine their use as industrial ceramic raw materials. Clay based ceramic materials are mostly used as building materials such as tiles and bricks [17]. Nowadays, by development of robocasting systems, clay based ceramics have started to be used as inks for building up 3D complex geometries.

In literature studies, the system generally used in biomedical industry for generating ceramic tissue scaffolds and artificial organs. It was stated in these studies that diameter of the nozzle, rheology of the paste (ink), its formulation and extruder rate were basic system parameters which affect manufactured part quality [11,18-20]. Different size of nozzle diameters such as $0.1 \mathrm{~mm}, 0.5 \mathrm{~mm}$ [21-22] and $1.5 \mathrm{~mm}$ $[18,23]$ have been generally used in previous studies. Although, the method most commonly used in biomedical industry, it is also promising method for manufacturing industrial ceramic products such as bathtubs, sinks and vases. However, the reported nozzle diameter values for biomedical applications are not effective for manufacturing industrial, large geometries. Because smaller nozzle diameters increase processing time. But there is lack of study about industrial application of the robocasting process and there are gaps for defining effective optimal process parameters for increasing process efficiency and product quality especially in industrial huge parts. In this study, it is aimed to determine the optimal process parameters for improving surface quality and dimensional accuracy of industrial ceramic parts. Nozzle diameter and material extruder rate were selected as process parameters and they were changed in different levels. Manufactured parts were inspected in terms of their dimensional accuracy and surface quality via precision measurement systems.

\section{MATERIALS AND METHODS}

In this study, clay based material which has been the most widely used material in the production of industrial ceramic parts was selected as feedstock for additive manufacturing of designed geometry. The content of the clay consists of $\mathrm{Al} 2 \mathrm{O} 3, \mathrm{Fe} 2 \mathrm{O} 3, \mathrm{SiO} 2, \mathrm{CaO}, \mathrm{MgO}, \mathrm{K} 2 \mathrm{O}$ and $\mathrm{Na} 2 \mathrm{O}$. Due to the confidentiality reasons of the company, where the study was conducted, detailed information on the content and proportions of the clay cannot be given.

DeltaWasp 3MT commercial robocasting system (Wasp, Italy), can be seen in Figure 1, was used for building up to samples. It has three different tool configurations selected according to the material form. These configurations are Wasp spitfire red extruder, Wasp pellet extruder and LDM Wasp extruder XL. In this study, LDM Wasp extruder XL tool configuration, which is suitable for the used clay and part dimensions, was used for part manufacturing. A photograph of the extruder and schematic illustration of the robocasting technique can be seen in Figure $1 \mathrm{~b}$ and 1c respectively.[24] 


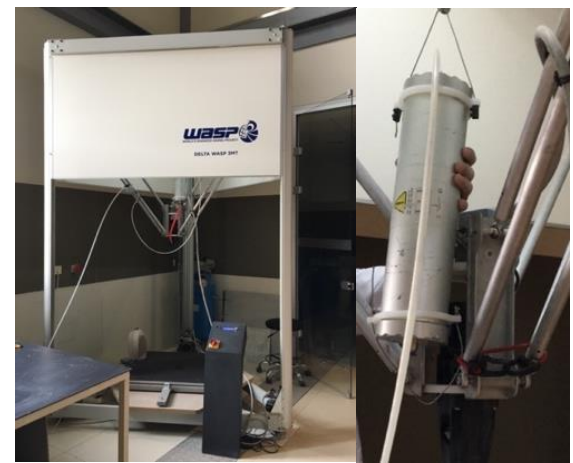

(a)

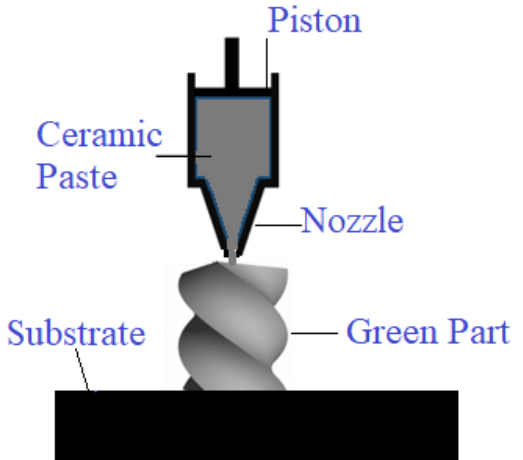

(c)

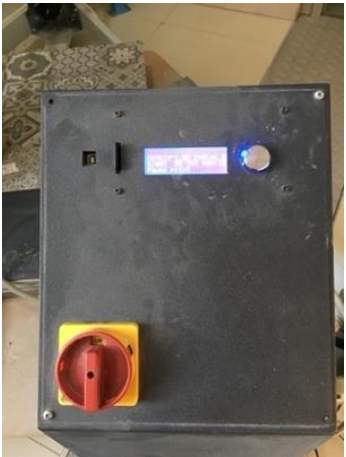

(d)

Figure 1. (a) Delta Wasp 3MT machine which is used for the case study. (b) LDM WASP Extruder XL. (c) Schematic illustrating the robocasting technique. (d) Control panel of the Delta Wasp 3MT.

The 3D printer system, used in this study, did not allow to define and alter the process parameters. Just the levels of the extruder rate which were stated on the system could be changed. Therefore, extruder rate levels and nozzle diameter were selected as the process parameters for the study. Nozzle diameter was changed in three levels while extruder rate was changed in two levels. Parameter sets and code of the experiments were listed in the Table 1. The nozzle diameter was set at the slicing process while the extruder rate level was set at the printing process by control panel which can be seen in the Figure 1d.

Table 1. Parameter sets for each part.

\begin{tabular}{ccc}
\hline \hline Part Name & $\begin{array}{c}\text { Nozzle } \\
\text { Diameter } \\
{[\mathbf{m m}]}\end{array}$ & $\begin{array}{c}\text { Extruder } \\
\text { Rate } \\
\text { Levels }\end{array}$ \\
\hline \hline A & 3 & 100 \\
B & 3 & 80 \\
C & 4 & 100 \\
D & 4 & 80 \\
E & 5 & 100 \\
F* $^{*}$ & 5 & 80 \\
\hline \hline
\end{tabular}

Flow rate of the material was altered by changing the extruder rate level where the pressure was constant at 7 bar throughout the production of all the parts. In addition, the nozzles used in the study were the standard nozzles, provided with the printer by the supplier company. Cleaning of the nozzle was done manually with alcohol and cloth when there was build-up on the tips of the nozzles during production. After the parts came out of the 3D printer, they were left to dry in the incubator at $100-150{ }^{\circ} \mathrm{C}$ degrees for 8 hours and then baked in an oven at $1330^{\circ} \mathrm{C}$ for 24 hours. During drying, only physical change was targeted and during firing, chemical changes were aimed to occur.

In order to determine the ability of the system, a hollow vase was designed in helical form, with sharp corners and free surfaces. One of the most important problem of ceramic robocasting process is building up high green bodies without losing their forms. To optimize the parameters for building up this kind of high geometries, the part was designed in $200 \mathrm{~mm}$ height. The design and dimensions of the part, which was designed to measure the performance of the printer system especially in sharp corners, can be seen in the Figure 2a-b. 


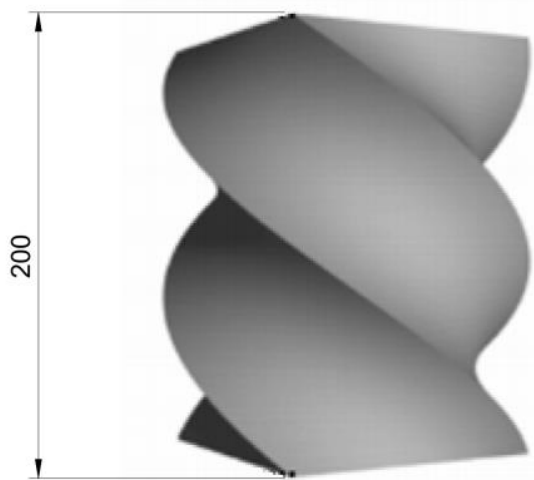

(a)

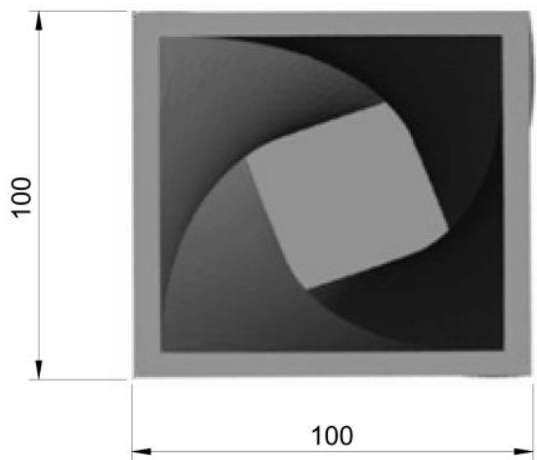

(b)

Figure 2. Design of the part. (a) Side view of the model (b) Top view of the model.

Wall thickness varied depending on nozzle diameter and the thickness of the base was twice the thickness of the layer to be selected. The layers of the built product were designed as a square section to analyze the behavior of the robocasting method at sharp corners with a large nozzle diameter $(\geq 3 \mathrm{~mm})$.

Dino-Lite digital microscope and Starrett HE400 profile projector, which can be seen in Figure 3a and Figure $3 b$, were used for geometrical and surface inspections. Dimensional measurements were applied by Hexagon CMM, can be seen in Figure 3c. Mahr M400 mechanical profilometer with granite table was used for determination of surface roughness. Measurements were taken from top surface and side surface of the parts. Roughness tester can be seen in Figure 3d.

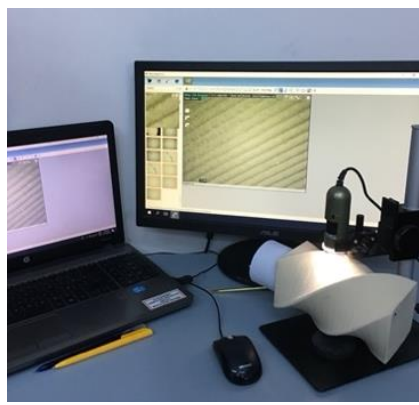

(a)

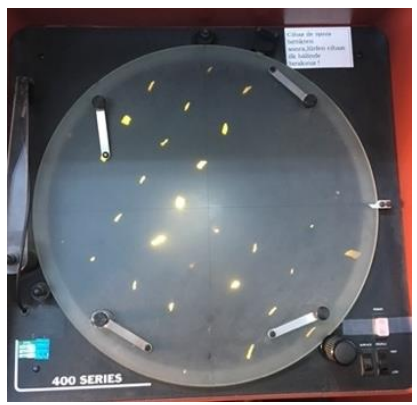

(b)

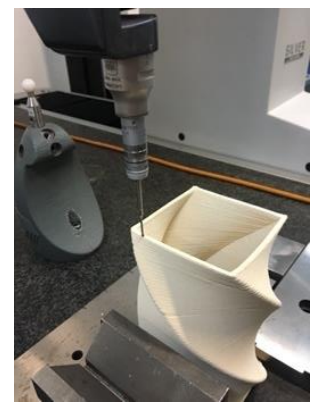

(c)

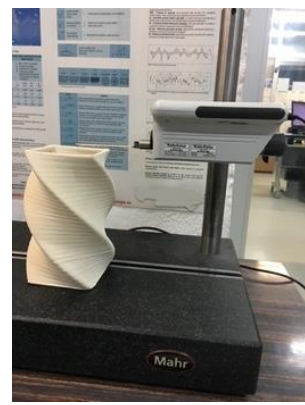

(d)

Figure 3. (a) Dino-Lite digital microscope (b) Starrett HE400 projector (c) Dimensional analysis with Hexagon CMM (d) Roughness analysis of top and side surfaces with Mahr M400 surface roughness tester.

\section{RESULTS AND DISCUSSION}

Robocasting process were applied by using the defined nozzle diameter and extruder rates. However, some problems were occurred during the deposition of the base layer of the designed parts especially Part A, D, E and F. At the beginning of printing process of the Part A, while the first layer was being deposited, nozzle did not leave the spilled material on the plate and the error occurred as a result of carrying it. This problem had to be manually intervened until the first layer of the base was ready, and the problem did not recur after the intervention. The problem can be seen in the Figure 5a.

For printing process of the Parts D, E and F it was observed that the first layer of the base was incomplete as shown in the Figure $4 \mathrm{~b}$. The main problem was incomplete flow of the ceramic paste as a result of lack of material coming from the nozzle. So, higher extruder rates were needed for the bigger nozzle diameters while building up the base layers. There was no problem at the base layer deposition of the Part B and C. 


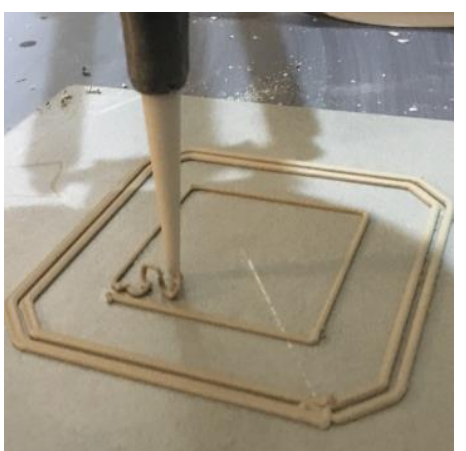

(a)

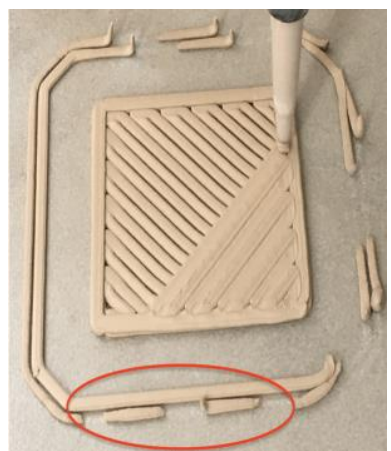

(b)

Figure 4. (a) The nozzle did not leave the spilled material on the plate (b) Base error due to intermittent spilling of material

During the process, another important problem was material collection around the nozzle such as given in Figure 5.

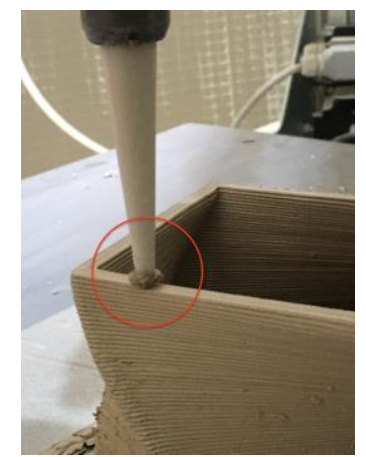

Figure 5. Collection of material around the nozzle.

This problem was experienced during the formation of the second layer of the base of all parts. After the second layer was formed, it appeared that this problem was not experienced in other layers as a result of manual cleaning of the nozzle. When this problem aroused, if it was not intervened for a long time, it created rough surfaces as given in the Figure 6.

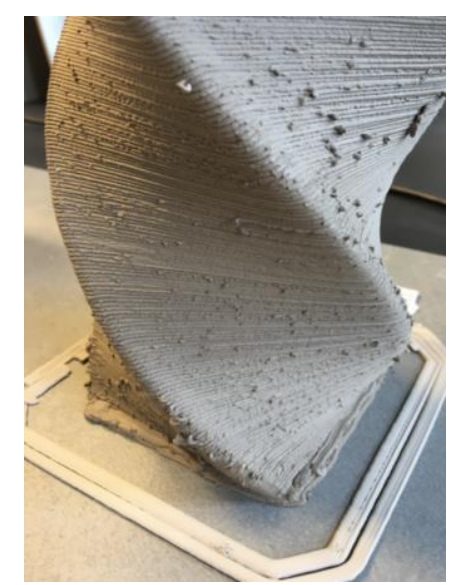

Figure 6. Rough surface problem.

After forming the base in the production of Part F, the extruder rate was adjusted to the predetermined rate and the formation of the layers started. However, with the predetermined extruder rate, the problem was encountered in the formation of the following layers as shown in the Figure 7. Therefore, the production of the part was stopped, and production failed for Part F. 


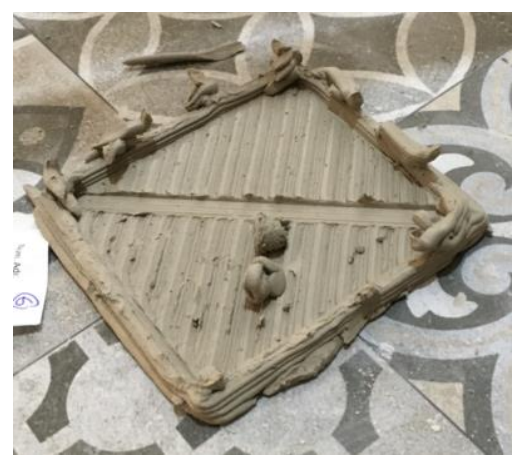

Figure 7. Part $\mathrm{F}$ which is incomplete.

After all building processes, manufactured parts were inspected in terms of their geometrical, dimensional, and surface properties.
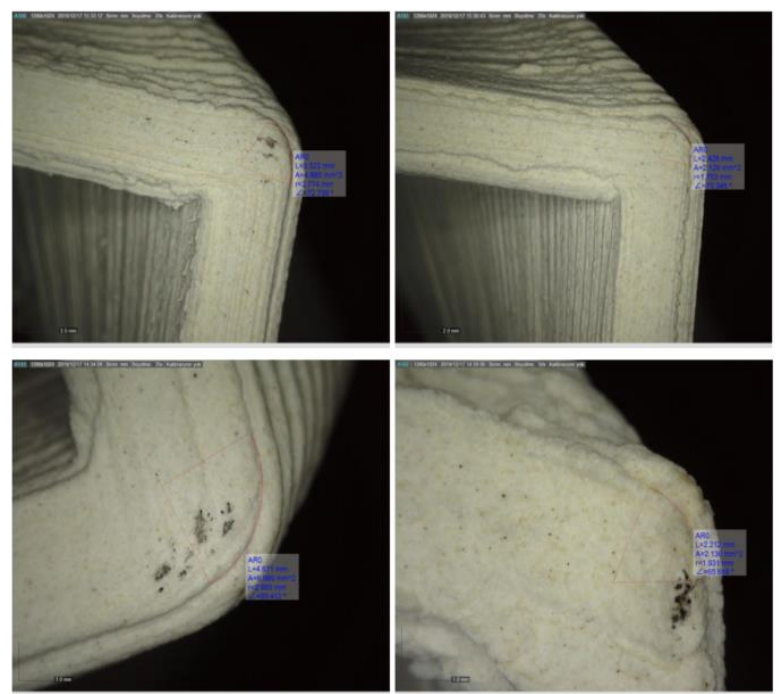

Figure 8. Radius measurement with digital microscope.

Due to the fact that the parts consist of square cross-sectional layers, a sharp corner was sought between the edges. As can be seen by visual inspections, round corners with radius values given in Table 2 were detected instead of sharp ones. Values of these radiuses were determined by digital microscope with the measurements which were performed as shown in the Figure 8. Minimum radius value achieved for Part B with $3 \mathrm{~mm}$ nozzle diameter and 80 level extruder rate while maximum was recorded for Part $\mathrm{C}$ build up with $4 \mathrm{~mm}$ nozzle diameter and 100 level extruder rate. Achieved layer thickness were also measured by the same microscope and listed in Table 2 below.

Table 2. Dimensional measurement results.

\begin{tabular}{cccccc}
\hline \hline Part Name & $\begin{array}{c}\text { Radius } \\
{[\mathbf{m m}]}\end{array}$ & $\begin{array}{c}\text { Layer } \\
\text { Thickness } \\
{[\mathbf{m m}]}\end{array}$ & $\begin{array}{c}\text { Wall } \\
\text { Thickness } \\
\mathbf{( t )}[\mathbf{m m}]\end{array}$ & $\begin{array}{c}\text { Height } \\
\text { Values } \\
{[\mathbf{m m}]}\end{array}$ & $\begin{array}{c}\text { Deviation } \\
\text { of Height } \\
\text { Value } \\
(\boldsymbol{\%})\end{array}$ \\
\hline \hline A & 2,744 & 0,761 & 4,636 & 167,660 & 16,17 \\
B & 1,753 & 0,828 & 5,114 & 168,128 & 15,94 \\
C & 2,993 & 0,820 & 5,748 & 164,977 & 17,51 \\
D & 2,154 & 0,784 & 3,923 & 163,952 & 18,02 \\
E & 1,931 & 0,781 & 4,768 & 163,947 & 18,03 \\
\hline
\end{tabular}

Dimensional accuracy of the parts was inspected by CMM measurements. Deviations from the wall thickness of the each vase samples were determined by taking the measurements from top surface of the vase samples shown in Figure 9. Also, height of the samples were measured five times and the mean 
values were reported in Table 2. Minimum wall thickness was measured for Sample D while maximum was recorded for Sample C. This is a result of different amounts of material being piled up depending on the nozzle diameter and material extruder rate. Deviation from the nominal height value $(200 \mathrm{~mm})$ was recorded as the highest for Part D and Part E this was because of the shrinkage of the green ceramic body during drying and baking processes. Minimum deviation for height was recorded for Part B.

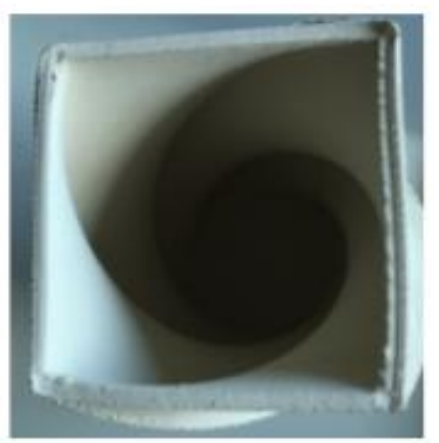

Figure 9. Top surface of the vase for wall thickness measurements.

Surface quality and base layer inspections were performed by digital microscope as shown in the Figure 10a. The errors described such as rough surface formation (Figure 10b), defects at end points (Figure 10c), and pitting on the surface (Figure 10d).

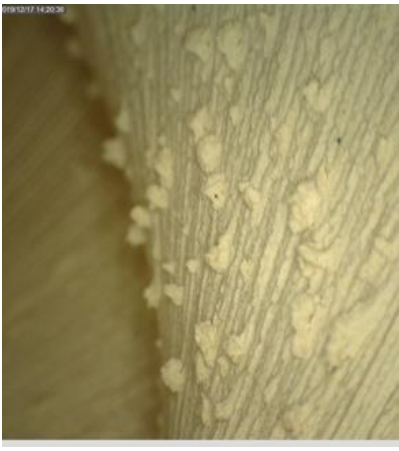

(a)

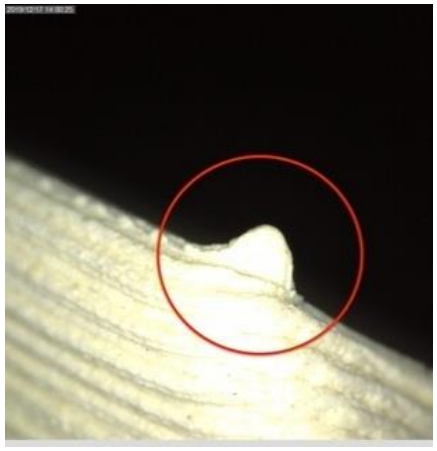

(b)

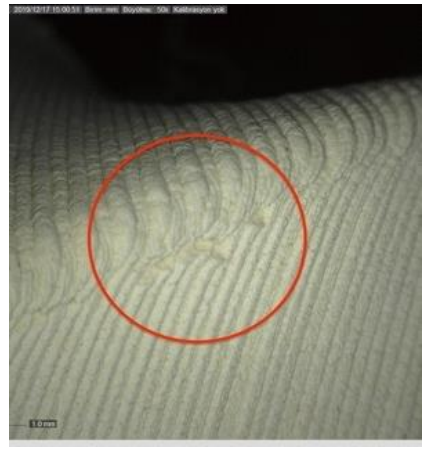

(c)

Figure 10. (a) Rough surface inspection of Part A. (b) Defect at end point of Part B. (c) Pitting on the surface of Part E.

The bases of the parts, which were the most problematic areas during production, were analyzed with a profile projector and a digital microscope. The base of the vases was designed to consist of two layers and the performance expected from the base was no cracks after baking. In the profile projector analysis, a yellow light was emitted from the light source on the projector as shown in the Figure 11a. If the light can pass through the part, it reaches the lens that is opposite the light source and reflects on the screen. The results of the base analysis of the pieces are given in Figure 11b-f.

Cracks were observed on Part A base which may aroused by air gaps between the layers. If air is trapped between the layers it may cause crack propagation during the firing of the green part [25, 26]. Moreover, the extruder rate of the machine should be adjusted according to the consistency of the mud as stated in [27]. 


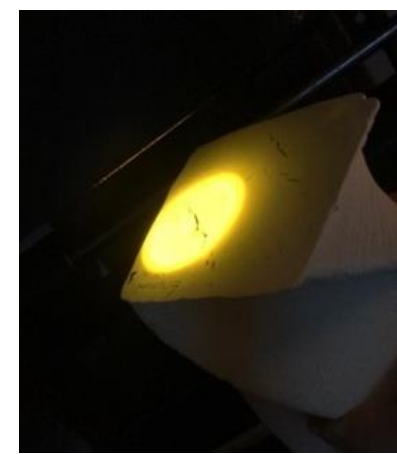

(a)

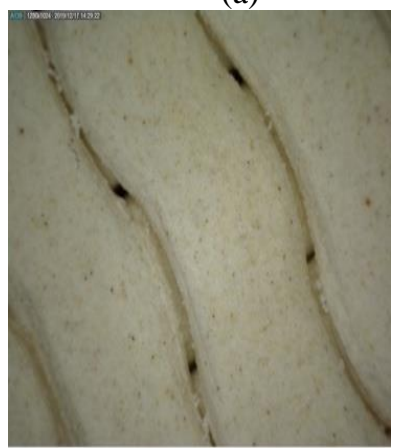

(d)

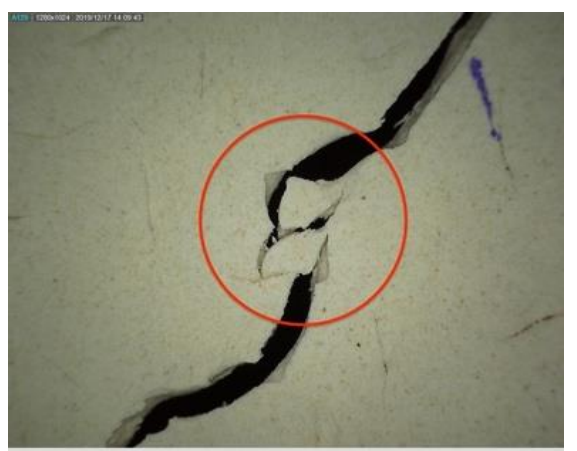

(b)

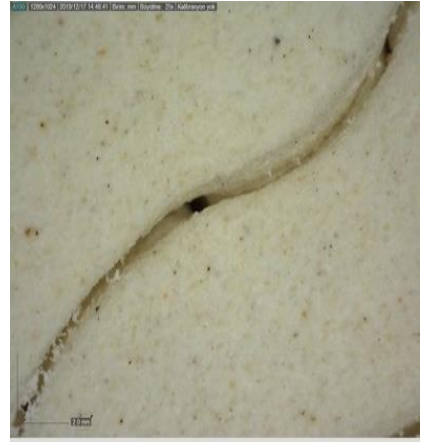

(e)

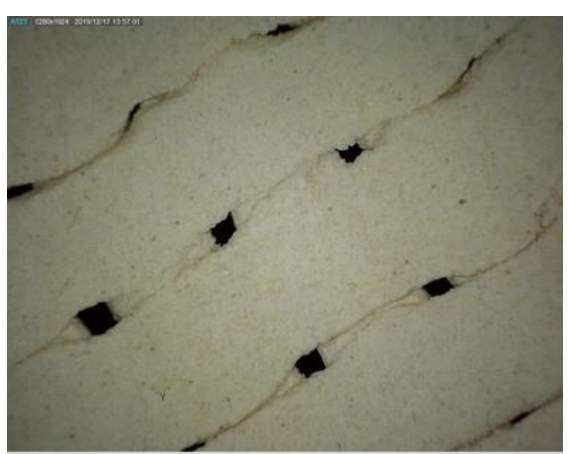

(c)

Figure 2. (a) Inspection of part A with a profile projector. (b) Part A's base. (c) Part B's base. (d) Part C's base. (e) Part D's base. (f) Part E's base.

Surface roughness measurements were taken from side and top surfaces of the parts. Results were reported in the Table 3 below. Minimum roughness value for side surface was measured for the Part B while it was measured on top surface of the Part C. The lowest Ra values were obtained by increasing the extruder rate when the nozzle diameter was increased. The maximum roughness value for both side and top surfaces was recorded for the Part E. Selecting proper extruder rate for the nozzle diameter is the most important factor on dimensional accuracy and surface quality of the parts. Although the best extruder rate for a $3 \mathrm{~mm}$ nozzle was 80 , the best extruder rate for a $5 \mathrm{~mm}$ nozzle was 155 .

Table 3. Roughness measurement results of side and top surfaces of the parts

\begin{tabular}{ccccccc}
\hline \hline \multirow{2}{*}{ Part Name } & \multicolumn{3}{c}{ Side Surface Roughness } & \multicolumn{2}{c}{ Top Surface Roughness } \\
\cline { 2 - 7 } & $\mathbf{R a}[\boldsymbol{\mu m}]$ & $\mathbf{R z}[\boldsymbol{\mu m}]$ & $\mathbf{R t}[\boldsymbol{\mu \mathbf { m }}]$ & $\mathbf{R a}[\boldsymbol{\mu m}]$ & $\mathbf{R z}[\boldsymbol{\mu m}]$ & $\mathbf{R t}[\boldsymbol{\mu m}]$ \\
\hline \hline A & 30,770 & 150,600 & 175,800 & 7,664 & 43,410 & 57,203 \\
B & 25,720 & 131,000 & 165,000 & 9,533 & 62,690 & 85,190 \\
C & 27,200 & 142,000 & 161,700 & 6,192 & 42,115 & 49,658 \\
D & 32,710 & 131,100 & 142,500 & 10,919 & 56,483 & 82,760 \\
E & 27,620 & 170,000 & 196,800 & 13,348 & 75,243 & 93,430 \\
\hline \hline
\end{tabular}

\section{CONCLUSION}

In this study, effect of robocasting process parameters like as nozzle diameter and extruder rate, on dimensional accuracy, surface quality and structural properties of ceramic vase parts were determined. By evaluating the results, it can be concluded that,

- During the formation of the base of the part, the material was collected around the nozzle while the second layer was pressed. If the nozzle was not cleaned after the base was formed, the formation of the structure would be rough. The extruder rate should also be changed as the nozzle diameter changes to a certain extent.

- While the main body of the part was being built up, if nozzle with larger diameter was used, the larger extruder rate should also be selected. Otherwise, the nozzle would start to pour the material incomplete. 
- Dimensional accuracy and surface quality were highly affected by process parameters. For the same nozzle diameter, it was difficult to obtain the sharp form at the corner points, as the extruder rate increases, more material was piled up.

- It was not possible to finalize building up process by $5 \mathrm{~mm}$ diameter nozzle with 80 extruder rate, because it was too low. So, for production of high quality parts in terms of dimensional accuracy and surface quality, it is important to select proper extruder rates for each nozzle diameter.

- Although cracks on the side surfaces of the piece experienced in a similar study were not revealed in this study, cracks were experienced on the base surface of Part A. In order to prevent these cracks, it will be beneficial to optimize the firing process parameters in future studies [28].

\section{ACKNOWLEDGEMENT}

The experiments and analysis were conducted at Kaleseramik Canakkale Kalebodur Seramik San. A.S. and Kalekalip Makine ve Kalip Sanayi A.S. The authors would like to thank for all the supports.

\section{REFERENCES}

1. Francisco J. M. and Antonia P. and Pedro M., "A Simple Graphite-Based Support Material for Robocasting of Ceramic Parts", Journal of the European Ceramic Society, Vol. 38, Issue 4, Pages 2247-2250, 2018.

2. Bandyopadhyay, A. and Bose, S., "Additive Manufacturing”, Pages 1-5, CRC Press, Taylor \& Francis Group, LLC., Boca Raton, FL, 2016.

3. Sagbas, B., "An Overview of Additive Manufacturing Methods for Biomedical Applications", Athens: ATINER'S Conference Paper Series, No: MEC2017-2378, Pages 1-15, 2018.

4. Sagbas, B., Gencelli, G. \& Sever, A., "Effect of Process Parameters on Tribological Properties of Ti6Al4V Surfaces Manufactured by Selective Laser Melting", Journal of Materials Engineering and Performance, Vol. 30, Issue 8, Pages 1-8, 2021.

5. Sagbas, B., "Post-processing effects on surface properties of direct metal laser sintered AlSi10Mg parts", Metals and Materials International, Vol. 26, Issue 1, Pages 143-153, 2020.

6. Revilla, R. I., Van Calster, M., Raes, M., Arroud, G., Andreatta, F., Pyl, L., ... \& De Graeve, I., "Microstructure and corrosion behavior of $316 \mathrm{~L}$ stainless steel prepared using different additive manufacturing methods: A comparative study bringing insights into the impact of microstructure on their passivity", Corrosion Science, Vol. 176, 108914, 2020.

7. Zhao, Y., Li, K., Gargani, M., \& Xiong, W., "A comparative analysis of Inconel 718 made by additive manufacturing and suction casting: Microstructure evolution in homogenization", Additive Manufacturing, Vol. 36, 101404, 2020.

8. Sagbas, B., "Surface texture characterization and parameter optimization of fused deposition modelling process”, Düzce Üniversitesi Bilim ve Teknoloji Dergisi, Vol. 6, Issue 4, Pages 1028-1037, 2018.

9. Sagbas, B., "Effect of Orientation Angle on Surface Quality and Dimensional Accuracy of Functional Parts Manufactured by Multi Jet Fusion Technology", European Mechanical Science, Vol. 4, Issue 2, Pages 47$52,2020$.

10. Erwin P. and Danwei Z. and Jun D., "Ceramic Robocasting: Recent Achievements, Potential, and Future Developments”, Advanced Materials, Vol. 30, Issue 47, 1802404, 2018.

11. Dietemann, B., Bosna, F., Lorenz, M., Travitzky, N., Kruggel-Emden, H., Kraft, T., \& Bierwisch, C., "Modeling robocasting with smoothed particle hydrodynamics: Printing gap-spanning filaments", Additive Manufacturing, Vol. 36, 101488, 2020.

12. Gibson,I. and Rosen, D. and Stucker, B., "Additive Manufacturing Technologies Rapid Prototyping to Direct Digital Manufacturing, First Edition, Springer US, New York, 2010. 
13. Deckers, J. and Vleugels, J. and Kruth, J., "Additive Manufacturing of Ceramics: A Review”, Journal of Ceramic Science and Technology, Vol. 05, Issue 04, Pages 245-260, 2014.

14. Feilden, E., “Additive Manufacturing of Ceramics and Ceramic Composites via Robocasting”, Ph.D Thesis, Imperial College London, Sep 2017,

15. Eqtesadi, S., Motealleh, A., Perera, F. H., Miranda, P., Pajares, A., Wendelbo, R., ... \& Ortiz, A. L., "Fabricating geometrically-complex B4C ceramic components by robocasting and pressureless spark plasma sintering”, Scripta Materialia, Vol. 145, Pages 14-18, 2018.

16. Ozkan, I., "Characteristics and Ceramic Properties of Turgutlu Clay", 6th International Congress \& Exhibition (APMAS2016), Acta Physica Polonica A, Vol. 131, Pages 7-9, Istanbul, 2016.

17. Carlova V., “Ceramic 3D Printing: A Revolution within Additive Manufacturing?", https://www.3dnatives.com/en/ceramic-3d-printing-170420194/, April 16, 2019. Access date: 20 March 2021.

18. Paterlini, A., Grill, S., Brouillet, F., Combes, C., Grossin, D., \& Bertrand, G., "Robocasting of self-setting bioceramics: from paste formulation to 3D part characteristics", Open Ceramics, Vol. 5, 100070, 2021.

19. Tabard, L., Garnier, V., Prud'Homme, E., Courtial, E. J., Meille, S., Adrien, J., ... \& Gremillard, L., "Robocasting of Highly Porous Ceramics Scaffolds with Hierarchized Porosity", Additive Manufacturing, Vol. 38, 101776, 2021.

20. Lei, L., Wei, Y., Wang, Z., Han, J., Sun, J., Chen, Y., ... \& Gou, Z., "Core-Shell Bioactive Ceramic Robocasting: Tuning Component Distribution Beneficial for Highly Efficient Alveolar Bone Regeneration and Repair", Acs Biomaterials Science \& Engineering, Vol. 6, Issue 4, Pages 2376-2387, 2020.

21. Schlordt, T., Keppner, F., Travitzky, N., \& Greil, P., "Robocasting of alumina lattice truss structures", Journal of Ceramic Science and Technology, Vol. 3, Issue 2, Pages 81-87, 2012.

22. Lorenz, M., Dietemann, B., Wahl, L., Bierwisch, C., Kraft, T., Kruggel-Emden, H., \& Travitzky, N., "Influence of platelet content on the fabrication of colloidal gels for robocasting: Experimental analysis and numerical simulation”, Journal of the European Ceramic Society, Vol. 40, Issue 3, Pages 811-825, 2020.

23. Wahl, L., Weichelt, M., Goik, P., Schmiedeke, S., \& Travitzky, N., "Robocasting of reaction bonded silicon carbide/silicon carbide platelet composites”, Ceramics International, Vol. 47, Issue 7, Pages 9736-9744, 2020.

24. Feilden, E., "Additive Manufacturing of Ceramics and Ceramic Composites via Robocasting”, PhD., Imperial College London, London, 2017.

25. Sevim S., \& Tutas V., "Üç Boyutlu Yazıcıların Çağdaş Seramik Sanatına Yansıması”, Sanat ve Tasarım Dergisi, Issue 26, Pages 627-645, 2020

26. Veteška, P., Hajdúchová, Z., Feranc, J., Tomanová, K., Milde, J., Kritikos, M., ... \& Janek, M. "Novel composite filament usable in low-cost 3D printers for fabrication of complex ceramic shapes", Applied Materials Today, 22, 100949, 2021.

27. Hakan E., \& Can E., "Bilgisayar Destekli Seramik Üretim Yöntemi Olarak Üç Boyutlu Yazıcılar ve Günümüz Koşullarında Uygulama Örneği”, Sanat ve Tasarım Dergisi, Vol. 6, Issue 1, Pages 1 - 15, 2016.

28. Hu F., Mikolajczyk T., Pimenov D., \& Gupta M., "Extrusion-Based 3D Printing of Ceramic Pastes: Mathematical Modeling and In Situ Shaping Retention Approach", Materials, Vol. 14, Issue 5, Pages 1137, 2021 . 